\title{
Economics of motion pictures: the state of the art
}

\author{
Darlene C. Chisholm • Víctor Fernández-Blanco • \\ S. Abraham Ravid • W. David Walls
}

Published online: 21 October 2014

(C) Springer Science+Business Media New York 2014

The motion-picture industry, with its global economic reach and high-stakes highly uncertain investments, transforms creative talent and inputs into multi-billion-dollar profits. The high-profile institutions, operations, exhibition patterns, distribution channels, and marketing strategies present opportunities to explore a wide range of economic research questions. Financial data, particularly on box-office and other revenue sources, provide researchers with a unique opportunity to gather extensive evidence and uncover empirical regularities that yield fundamental insights into strategic investment, organizational design, incentive-compatible contracting, product design, advertising, and cross-cultural consumer experiences, among other areas of basic economic research.

This special issue comprises five papers that explore some of these areas, creatively exploiting publicly available data and well-documented industry institutions.

The first paper presents evidence on financial outcomes for remakes, an alternative form of brand extension. The second paper studies sequel films in the

D. C. Chisholm ( $\square)$

Suffolk University, Boston, MA, USA

e-mail: darlene.chisholm@suffolk.edu

V. Fernández-Blanco

ECO2011-27896, University of Oviedo, Oviedo, Spain

e-mail: vfernan@uniovi.es

S. Abraham Ravid

Yeshiva University, New York, NY, USA

e-mail: ravid@yu.edu

W. David Walls

University of Calgary, Calgary, Canada

e-mail: wdwalls@ucalgary.ca 
context of brand extension and relational contracting, with a novel insight into the relationship between the relative bargaining power of creative talent and studios, and the level of investment in advertising. The next paper provides evidence on how films are allocated to screens during their theatrical runs, and how these allocation strategies relate to the status of distributors as "major" and "non-major" players. The final two papers explore international motion-picture markets and the importance of cultural discounting in the financial success of films in the Australian and Korean markets.

We discuss each paper in turn and place the authors' findings in the broader context of recent research in motion-picture economics. We conclude by discussing promising avenues for future research in this growing field of study.

\section{Movie profitability, sequels, and remakes}

The list of top-10 grossing movies in 1998 included no sequels or remakes, and, arguably, no clear franchises. ${ }^{1}$ By 2012, the picture had changed dramatically. Seven out of the 10 top movies of that year were sequels or franchises (boxofficemojo.com). Whereas academia often analyzes industry trends after they have occurred, in this case, interestingly, it seems that the "real world" followed academia.

Until the mid-1990s, much of the research on the economics of the movie industry suffered from data limitations and generally included only restricted explorations of small data sets. In the mid- and late 1990s, the literature on the determinants of movie profitability took a step forward with the availability of larger data sets and more sophisticated econometric analysis (see Ravid 1999; Ravid and Basuroy 2004; De Vany and Walls 1996, 1999, 2002; Simonoff and Sparrow 2000; Vogel 2001; Fee 2002; Einav 2007; Palia et al. 2008; and others).

De Vany and Walls (1996, 1999, 2002) and Ravid (1999) were among the first to statistically evaluate if and when one can predict which movies will be successful and what factors should be important in the calculus of studios. Surprisingly, stars did not matter for revenues or rates of return on movies. This was first established in Ravid (1999) and De Vany and Walls (1999) and confirmed by later work (for example, Elberse 2007). The type of movie mattered (generally family movies sell better, everything else equal: see Ravid 1999; Simonoff and Sparrow 2000; De Vany and Walls 2002; Fee 2002). Fernández-Blanco et al. (2013) confirmed these results after controlling for the presence of endogeneity when estimating demand functions with average prices.

However, Ravid (1999) also found that sequels deserved much more attention. Sequels were not necessarily more successful than the original movies; in fact, they generally (but not always) trailed the original. They did, however, perform much better than the median original movies, and more importantly, they were low-risk high-return enterprises, a prospect that is extremely difficult to find in an industry where supposedly "nobody knows anything." Palia et al. (2008) found that,

\footnotetext{
${ }^{1}$ Earnings are theatrical box-office receipts in the US and Canada.
} 
accordingly, studios rarely co-finance sequels. They prefer to co-finance the high risk part of their portfolio, conforming to some alliance theories.

Industry thinking has shifted slowly in the early part of this century, and gradually, the list of top-selling movies has become an endless list of sequels and franchises (see Fernández-Blanco et al. 2014). Incidentally, this also created an unprecedented disconnect between the Academy awards best picture list (which features generally original movies) and the top-grossing movies, which, as noted, are mostly sequels.

In the first paper in this special issue, Bohnenkamp et al. (2015) provide a very interesting perspective on this matter which straddles academia and industry. Their paper is among the first examinations of remakes. Many people consider sequels to be similar to remakes. However, while both types of enterprise are technically "brand extensions" in marketing language (see Hennig-Thurau et al. 2009), Bohnenkamp et al. (2015) find that by many measures, remakes neither increase revenues nor reduce financial risk. In fact, successful remakes follow a rather lukewarm original or even a failed adaptation of a well-known book. In other words, whereas a huge success should be followed by a sequel, a huge success should not be remade ("Psycho" is possibly the most interesting example of this principle: A very successful movie by Alfred Hitchcock was remade verbatim by a well-known director, Gus Van Sant, but failed miserably at the box-office). A successful remake should then follow an unsuccessful adaptation of potentially great material. This insight makes much sense, in particular today, when everybody can watch any movie any time-why watch an inferior remake if the original is available? However, this very important distinction between sequels and remakes seems to have eluded some studio executives who kept turning out unsuccessful remakes. Therefore, the Bohnenkamp et al. (2015) paper, which thoroughly documents this idea, may lead to a change of thinking by academics and studio executives alike.

In recent years, some work has begun to explore drivers of film profitability beyond film characteristics, and again, there is some interesting connection between academic work and industry thinking.

Recent work explores the role of screenplays in the success of the resulting movies (see Eliashberg et al. 2007; Luo 2014; Goetzmann et al. 2013; Harris et al. 2013). Even though a screenplay sale is far removed from the finished product, it has a decisive, discernable economic effect on the resulting movie. Goetzmann et al. (2013) find that price paid for screenplays can predict the success of future movies. This is also consistent with Eliashberg et al. (2007). In related work, John et al. (forthcoming 2015) find that directors, and in particular the more successful ones, have a clear effect on the profitability of movies. In other words, unlike stars, directors do matter; this finding is also consistent with De Vany (2004). The Spanish case is quite different: Stars affect box-office performance positively and directors affect it negatively (Fernández-Blanco and Prieto-Rodríguez 2003).

In 40 years of Academy awards, the writer for the best picture was also nominated for best writer in $98 \%$ of the cases. In $75 \%$ of the cases, the writer of the best picture also won an Oscar for writing. Very interestingly, if we turn to the "Razzies," the semi-satirical "award" for the worst movie of the year, every writer for the worst film since the inception of the award was nominated for the worst 
screenplay "award," and in $82 \%$ of the cases, they also "won." Similarly, $98 \%$ of the directors of the best picture were nominated for best director and they won in $83 \%$ of the cases. The Razzies present a similar picture with directors being nominated in $97 \%$ of the cases and "winning" in $67 \%$ of the cases (see Goetzmann et al. 2013).

So we have come full circle. Family films and sequels make money. Remakes are a much more uncertain proposition. However, emerging work seems to point to the crucial role of the essential substance of film enterprise: a writer and a director.

\section{Advertising and critical reviews}

In recent years, several marketing studies have estimated the impact of critical reviews and advertising on movie revenues. Advertising is generally correlated with movie budgets; in other words, large blockbusters tend to have large advertising budgets, whereas low-budget movies are rarely pushed hard. This correlation makes statistical tests of the role of aggregate advertising dollars difficult. However, when done, tests show that advertising can increase revenues (see Ho et al. 2009).

The role of critics has been a focus of marketing research for nearly two decades. Eliashberg and Shugan (1997) were the first to pose the question of whether critics were "predictors" (of how a movie would perform) or "influencers" (whose expert opinions drive attendance). Eliashberg and Shugan (1997) suggest that the prediction role is more important, but Basuroy et al. (2003) show that both roles matter; in other words, revenues throughout the run are correlated with critical reviews. The role of expert reviews is explored in various ways in other papers, such as Holbrook (1999) and others.

In recent years, as internet and posted user reviews have proliferated, several studies have tried to evaluate the impact of user reviews (so-called word-of-mouth) on the success of motion pictures (see Liu 2006; Chintagunta et al. 2010). Liu (2006) finds that internet buzz (volume) matters, but Chintagunta et al. (2010), who use more granular data and adjust for endogeneity, conclude that it is the valence of internet reviews that drives revenues. Basuroy and Ravid (2014), who extend this literature to include both expert opinions and user reviews, find that internet reviews matter, but expert opinions carry more weight, even with today's prolific internet usage.

\section{Relational contracting and the theory of the firm}

In the next paper in this special issue, Ma et al. (2015) examine the role of bargaining power in influencing studios' expenditures on advertising and promoting sequel films. The brand-extension literature suggests that sequels, with their inherent brand-name recognition, should require studios to invest less in advertising relative to non-sequels. The authors consider the alternative hypothesis that increased bargaining power of lead actors in sequel films leads to greater levels of studio advertising. Their approach is grounded in the 
transaction-cost literature (Williamson 1985; Williamson and Ghani 2012), motivated by the importance of bargaining power in influencing ex post investments in relationships characterized by high degrees of asset specificity, as is the case with sequel films. Using data on recent sequel films, the authors find that pre-release advertising of sequel films is positively related to leading actors' star power. Building on Sood and Drèze (2006), the results are robust to controls for sequel title similarity, as well for the original films' box-office performance, genre, and studio status.

The transaction-cost framework has proven useful in other motion-pictures industry analyses. Gil (2009) finds that vertical integration between film distributors and exhibitors resolves the tension between each party's incentives in a revenue-sharing agreement: When the distributor and exhibitor are separately owned, distributors seek to lengthen a film's run, whereas exhibitors, who directly benefit from total attendance through concession sales, prefer to show newer releases sooner. In related work, Gil and Lafontaine (2012) draw on the principal-agent model and find that, given the high degree of uncertainty in the box-office success of any given film, revenue-sharing contracts serve to satisfy the participation constraint of the exhibitors. The role of risk in choosing to co-finance films has been explored in both Goettler and Leslie (2005) and Palia et al. (2008); the former find that co-financing is more likely for films with larger budgets, while the latter find that project-specific risk increases the likelihood of a co-financing agreement and that therefore, sequels and family films, which have lower risk and higher returns than other types of films, are generally solely financed by one studio. Applying principles from the theory of the firm, with specific consideration of how contracting parties perceive and mitigate risk in their contracting terms, continues to serve as a fruitful avenue in motion-pictures industry studies.

In addition to exploiting the extensive data on creative talent and on film performance and characteristics publicly available on websites such as imdb.com and the-numbers.com, research on distributor-exhibitor relationships has benefitted from scholars' direct access to industry sources and detailed contractual arrangements. Early work resulting from such access includes Filson et al. (2005), who study contracting terms between distributors and exhibitors from the St. Louis exhibition market and find that both risk aversion, transaction costs, and repeat contracting influence contracting terms. More recently, Gil (2013) examines relational versus formal distributorexhibitor contractual arrangements, using extensive data from a Spanish film exhibitor, finding that formal contracting is more likely to be adopted when the exhibitor is more likely to renege on the contract, as with films with strong box-office potential. Future research based on firm-level data and extensive institutional knowledge from industry sources will continue to broaden the scope of empirical contributions to the theory of the firm while remaining relevant to industry practitioners, including further study of contractual relationships between creative talent (actors, screenwriters) and studios. 


\section{Strategic theater allocation}

The Prieto-Rodríguez et al. (2015) paper in this issue analyzes the way in which the allocation of theater screens to films differs between major and non-major movie distributors and the implications this has on the market power of the different types of distributors. The allocation of screens to films is palpably important:

A film's release pattern represents its distributor's strategy for acquiring the demand information that will guide subsequent decisions. The release also sets the initial supply of engagements.... Following the film's initial release, decisions to expand engagements or lengthen its run are both centralized and decentralized.

De Vany and Walls (1997)

Gutiérrez-Navratil et al. (2014) identify a clear asymmetry between the effect of past and future film releases; they find specifically that rival movies released up to 3 weeks after a given film's release have a higher impact on a movie's market share than rival movies released up to 3 weeks before a film's release. $^{2}$

The contract to exhibit a motion picture will specify how supply adapts to changes in demand, and there are a number of papers that describe or analyze motion-picture contracts (e.g., Chisholm 1997, 2004; De Vany and Walls 1997; Filson et al. 2005; see also Chisholm and Norman (2006) on exhibition programming). However, motion-picture exhibition contracts are proprietary and for that reason it is exceedingly difficult to conduct detailed empirical analysis on distribution strategies. Prieto-Rodríguez et al. (2015) employ a Hausman and Taylor (1981) estimator to quantify theater elasticities of boxoffice revenue that can differ across major and non-major distributors. The substantive finding of their research is that the theater elasticity for non-major distributors is close to unity throughout a film's theatrical run and significantly higher than the estimated theater elasticity for major distributors. This finding can be explained by (1) contractual incentives that induce exhibitors to allocate more theaters or (2) high bargaining power on the part of the distributors relative to the exhibitors. The implication drawn by the authors is that major distributors have more bargaining power than non-major distributors and that this impacts theatrical market outcomes.

Controversy has surrounded contracting practices in the film industry since its earliest days, with exhibitor-distributor contracting practices being particularly important in the famous Paramount cases of the 1940s that fundamentally altered the American film industry. The economics of contracting in the film industry appears to be an important area for future research.

\footnotetext{
${ }^{2}$ The analysis used panel data techniques to control for unobserved heterogeneity among the movies released in five countries (France, Germany, Spain, United Kingdom, and United States) during the period 2000-2009.
} 


\section{International movie markets and cultural distance}

International markets and trade flows are topics of increasing interest in the economics of the movie industry. This fact may be motivated by several features of the international motion-picture industry.

First, there is the phenomenon of "unbalanced" international trade flows. From the end of the First World War, Hollywood has dominated the international markets, particularly in Europe (Gomery and Pafort-Overduin 2011). And this dominance is being reinforced at the present time: In 2013, the market share of US films in the European Union reached $69.1 \%$, the highest market share in the past 10 years. At the same time, the market share of non-US films in the USA and Canada was only $5.4 \%$ (European Audiovisual Observatory 2014). Since the middle of the 1920s, European countries have been concerned about this reality and have implemented different protectionist measures against motion-picture imports in order to preserve domestic production of cultural goods, local cultures, and languages. These policies, which probably reached their peak when France introduced the concept of cultural exemption during GATT negotiations in 1993, are based on the idea of protecting the production of national culture; otherwise, countries may face a market failure in terms of positive externalities and public good characteristics. However, such policies could also be used in defense of national cultural production, which is not quite the same thing (Mas-Colell 1999). In this case, a protectionist barrier would limit the advantages of Hollywood movies in terms of English language, stars, popularity or economies of scale (Marvasti and Canterbery 2005). On the other hand, Europe frequently denounces the dumping of Hollywood films, especially given that the Webb-Pomerane Act explicitly permits monopolistic practices in foreign markets (Scott 2002).

Second, there is the increasing contribution of foreign markets to US motionpicture box-office revenues. Since 1980, motion-picture box-office sources for American-made films have dramatically changed. At the same time that revenues from other windows and ancillary markets became the main sources of income, US domestic box-office was being displaced by overseas box-office receipts. The notable increase in exports of US films has led to a new box-office profile: At the end of the eighties, less than $40 \%$ of worldwide theatrical revenues of major studios came from domestic markets; whereas, according to Motion Picture Association of America (MPAA), in 2013, this percentage had increased to $69.6 \%$. Simultaneously, foreign box-office has become a key part of the US industry's profits. As this change was occurring, industry and researchers began paying more attention to the behavior of foreign markets and their links with domestic box-office earnings. Ravid (1999) was the first and one of the few papers to include data analysis of international revenues rather than just US box-office or individual countries. He found that there are different factors that determine international versus domestic and home entertainment revenues. The changing relative importance of domestic and international markets is associated with a substantial change in the attributes of films produced by the Hollywood industry (Walls and McKenzie 2012). Thus, increasing international profitability is of growing interest in international marketing 
campaigns, releasing strategies, discussion about the determinants of domestic and foreign box-office, and how to preserve existing markets or conquer new ones.

Third, in some sense, these previous comments are only part of a bigger idea, namely the globalization of the movie industry. This is a reality with multiple characteristics that comprise risks and opportunities. The traditional major studios are now international conglomerates that take advantage of economies of size and agglomeration, particularly in distribution, a part of the value of chain that is especially globally oriented. Globalization can be seen as a menace in terms of standardization of cultural products and reinforcement of the Hollywood style as the worldwide language of movies. However, globalization of this industry also creates opportunities to open new and cheaper windows to minority products and cultures. Something similar can be said in relation to digitization and new technologies (Finney 2010).

Cultural distance, often measured by means of language, suggests another argument frequently used when analyzing international movie markets (Hanson and Xiang 2011). Proximity, or lack of comprehension of a language, commonly English, is a powerful determinant of the presence, and then success, of movies in foreign countries. On the other hand, globalization and new technologies can contribute to a higher cultural hybridization by opening new channels to local or minority products. And hybridization in the population can also be a factor that reduces the cultural discount, not only in favor of American products but also in the opposite direction, reducing the distance to languages other than English, as the recent success of "Instructions Not Included" at the American box-office illustrates.

Park's (2015) paper, in this special issue, contributes to this debate by treating the cultural discount and changes in the Australian population composition as determinants of movie imports. The paper offers a notable contribution to the area of international trade in motion-picture services. The author uses the one-way media flow model to consider both market size and cultural diversity as determinants of movie imports in Australia. Park concludes that the number of movies Australia imports from a country increases, and they perform better in terms of Australian box-office, when they come from larger markets and from countries with a short cultural distance. In sum, a greater exposure to foreign cultures can change cultural tastes and then increase diversity in movie imports; at the same time, these changes need a longtime period to be significant.

In sum, we can conclude that local markets are less and less relevant, and even if we are interested only in the big screen, we need to take a global perspective.

\section{Consumers' reception of imported and domestic films}

In the same vein, the Moon et al. (2014) paper in this special issue is an analysis of the Korean exhibition market in which domestically produced Korean films compete with foreign films - primarily Hollywood productions-in the context of culturally unique viewers.

Recent studies by Lee $(2006,2008)$ have examined the box-office performance of Hollywood films in East Asian markets-Hong Kong, Taiwan, South Korea, Japan, 
Malaysia, Singapore, and Thailand-but these studies have not explored competition within those movie markets. Instead, those studies quantified the correlation between Hollywood film revenues in the USA and the revenues of the same Hollywood films in individual foreign countries. In contrast to the analysis of how well Hollywood films do in particular international markets, the earlier papers of Walls (1997, 1998) investigated and empirically modeled competition within the Hong Kong theatrical movie market between domestic Cantonese films and imported Hollywood films, and Walls (2009) extended the analysis to competition in Thailand between domestic Thai films and imported non-Thai films. McKenzie and Walls (2012) examined competition in the Australian exhibition market between Australian and Hollywood films and found that even though the domestic films were advertised more heavily and released more widely, they still earned lower revenues at the box-office.

A well-articulated and sensible explanation of global media market dominance is that the combination of scale economies in production and cultural discount in consumption results in an equilibrium in which media markets are dominated by firms located in countries with relatively large domestic markets. The cultural discount refers to the lower demand for foreign products that are less familiar to consumers in terms of social values, historical perspective and context, and language. The cultural discount disproportionately affects producers from small countries, because a larger proportion of the global market culturally discounts their products. In contrast, producers from larger countries serve their larger domestic markets without any cultural discount in addition to a certain amount of effective demand from culturally distant markets. The larger effective markets for the larger countries permit firms in these countries to benefit from scale economies in the production of media products.

Hoskins and Mirus (1988), Hoskins and McFayden (1991), Marvasti (1994, 2000), Marvasti and Canterbery (2005), Waterman (1988), and Wildman and Siwek (1988), among others, provide thorough explorations of this type of model in relation to both film and television markets. In the context of the motion-picture market, this model appears to be an accurate depiction in the pre-1990s period when non-US theatrical revenues were smaller than domestic revenues. One could think of US demand as driving Hollywood production and the Hollywood supply of films to the rest-of-world market as a residual rather than as a driving force.

A substantial body of work that tests the cultural discount hypothesis in the context of the motion-picture industry has evolved over the past decade. Many studies, in particular the earlier studies in this literature, rely on aggregate or macrolevel data to test the cultural discount model. For example, Fu and Sim (2010) and Oh (2001) investigate international trade in films and find support for the cultural discount hypothesis. Jayakar and Waterman (2000) analyze US film exports, and Lee (2002) investigates competitive balance of film trade between the USA and Japan, both studies finding support for the cultural discount hypothesis of media market dominance. Most of the recent studies leverage highly disaggregated filmlevel data through the application of modern econometric analysis. Fu and Lee (2008) study the market for films in Singapore, Lee (2006) examines the market for films in Hong Kong, and Lee $(2008,2009)$ test the cultural discount hypothesis in a 
number of East Asian countries, while Walls and McKenzie (2012) quantify cultural discount of Hollywood films in Australia, France, Germany, Mexico, Spain, and the UK.

Against the backdrop of previous research, the Moon et al. (2014) paper finds that in the case of the Korean movie market, locally produced films generate polarized viewer expectations and that this leads to domestic films having higher ticket sales and longer life lengths at the box-office. The substantive issue raised in the paper is the importance of global convergence versus local divergence and the extent to which film producers may find it beneficial to customize films for specific culturally unique markets.

\section{Further directions for research}

The movie industry presents significant opportunities for further research on topics central to economic analysis. Formally, estimating demand parameters for both theatrical and on-demand viewing using discrete-choice models of product differentiation and structural demand estimation provides an opportunity to deepen our understanding of demand characteristics. Further exploration of the role of social media in influencing box-office outcomes will enhance our understanding more generally of the importance of both critical reviews and word-of-mouth in film revenues, and of how this balance evolves over time as social media gains in both cultural prominence and prevalence. As viewing technology changes, and consumers view content on a wider range of media, such as handheld devices versus bigscreen theaters, will content production bifurcate, with content and production processes and organization diverging over time, depending on expected "screen" size? And how will fundamental release and screen-allocation strategies, along with distribution channels, change as platforms for viewing content proliferate? How do changes in technology impact the costs of enforcing studios' intellectual property rights and of deterring electronic content theft and piracy? The availability of a wide range of financial data, film characteristics, filmographies of creative talent, releasing strategies, and global revenue performance provides a promising base for robust empirical and institutional analysis of these and other fundamental questions in motion-pictures economics.

\section{References}

Basuroy, S., Chatterjee, S., \& Ravid, S. A. (2003). How critical are critical reviews? The box office effects of film critics, star power, and budgets. Journal of Marketing, 67(4), 103-117.

Basuroy, S., \& Ravid, S. A. (2014). How relevant are experts in the internet age? Evidence from the motion pictures industry. Working Paper, University of Oklahoma.

Bohnenkamp, B., Knapp A., Hennig-Thurau, T., \& Schauerte, R. (2015). When does it make sense to do it again? An empirical investigation of contingency factors of movie remakes. Journal of Cultural Economics, (Special Issue on Motion-Pictures Economics, forthcoming). 
Chintagunta, P. K., Gopinath, S., \& Venkataraman, S. (2010). The effects of online user reviews on movie box office performance: Accounting for sequential rollout and aggregation across local markets. Marketing Science, 29(5), 944-957.

Chisholm, D. C. (1997). Profit-sharing versus fixed-payment contracts: Evidence from the motionpictures industry. Journal of Law, Economics and Organization, 13(1), 169-201.

Chisholm, D. C. (2004). Two-part share contracts, risk, and the life cycle of stars: Some empirical results from motion-pictures contracts. Journal of Cultural Economics, 28(1), 37-56.

Chisholm, D. C., \& Norman, G. (2006). When to exit a product: Evidence from the U.S. motion-picture exhibition market. American Economic Review, 96(2), 57-61.

De Vany, A. (2004). Motion picture directors: Luck, talent and rewards. In V. A. Ginsburgh (Ed.), Chapter 1 in Economics of art and culture: Invited papers at the 12th international conference of the association of cultural economics international, Contribution to Economic Analysis Book Series, Vol. 260. Baltagi, B. H. and Sadka, E., Series Editors (pp. 2-17). Elsevier, Amsterdam.

De Vany, A., \& Walls, W. D. (1996). Bose-Einstein dynamics and adaptive contracting in the motion picture industry. The Economic Journal, 106(439), 1493-1514.

De Vany, A. S., \& Walls, W. D. (1997). The market for motion pictures: Rank, revenue and survival. Economic Inquiry, 35(4), 783-797.

De Vany, A., \& Walls, W. D. (1999). Uncertainty in the movie industry: Does star power reduce the terror of the box office? Journal of Cultural Economics, 23(4), 285-318.

De Vany, A., \& Walls, W. D. (2002). Does Hollywood make too many r-rated movies? Risk, stochastic dominance, and the illusion of expectation. Journal of Business, 75(3), 425-451.

Einav, L. (2007). Seasonality in the US motion picture industry. RAND Journal of Economics, 38(1), $127-145$.

Elberse, A. (2007). The power of stars: Do star actors drive the success of movies? Journal of Marketing, 71(4), 102-120.

Eliashberg, J., Hui, S. K., \& Zhang, Z. J. (2007). From story line to box office: A new approach for greenlighting movie scripts. Management Science, 53(6), 881-893.

Eliashberg, J., \& Shugan, S. M. (1997). Film critics: Influencers or predictors? Journal of Marketing, 61(2), 68-78.

European Audiovisual Observatory (2014). Focus 2014-World Film Market Trends.

Fee, C. E. (2002). The costs of outside equity control: Evidence from motion picture financing decisions. Journal of Business, 75(4), 681-711.

Fernández-Blanco, V., Ginsburgh, V., Prieto-Rodríguez, J., \& Weyers, S. (2014). As good as it gets? Blockbusters and the inequality of box office results since 1950. In J.C. Kaufman, D.K. Simonton (Eds.), Chapter 12 in The Social Science of Cinema (pp. 269-285). Oxford University Press: New York.

Fernández-Blanco, V., Orea, L., \& Prieto-Rodríguez, J. (2013). Endogeneity and measurement errors when estimating demand functions with average prices: An example from the movie market. Empirical Economics, 44(3), 1477-1496.

Fernández-Blanco, V., \& Prieto-Rodríguez, J. (2003). Building stronger national movie industries: The case of Spain. Journal of Arts Management, Law and Society, 33(2), 142-160.

Filson, D., Switzer, D., \& Besocke, P. (2005). At the movies: The economics of exhibition contracts. Economic Inquiry, 43(2), 354-369.

Finney, A. (2010). The international film business: A market guide beyond Hollywood. New York: Routledge.

Fu, W. W., \& Lee, T. (2008). Economic and cultural influences on the theatrical consumption of foreign films in Singapore. Journal of Media Economics, 21(1), 1-27.

Fu, W. W., \& Sim, C. (2010). Examining international country-to-country flow of theatrical films. Journal of Communication, 60(1), 120-143.

Gil, R. (2009). Revenue sharing distortions and vertical integration in the movie industry. Journal of Law, Economics and Organization, 25(2), 579-610.

Gil, R. (2013). The interplay of formal and relational contracts: Evidence from movies. Journal of Law, Economics and Organization, 29(3), 681-710.

Gil, R., \& Lafontaine, F. (2012). Using revenue sharing to implement flexible prices: Evidence from movie exhibition contracts. Journal of Industrial Economics, 60(2), 187-219.

Goettler, R. L., \& Leslie, P. (2005). Cofinancing to manage risk in the motion picture industry. Journal of Economics and Management Strategy, 14(2), 231-261. 
Goetzmann, W. N., Ravid, S. A., \& Sverdlove, R. (2013). The pricing of soft and hard information: Economic lessons from screenplay sales. NBER Working Paper. Journal of Cultural Economics, 37(2), 271-307.

Gomery, D., \& Pafort-Overduin, C. (2011). Movie history: A survey (2nd ed.). New York: Routledge.

Gutiérrez-Navratil, F., Fernández-Blanco, V., Orea, L., \& Prieto-Rodríguez, J. (2014). How do your rivals' releasing dates affect your box office? Journal of Cultural Economics, 38(1), 71-84.

Hanson, G., \& Xiang, C. (2011). Trade barriers and trade flows with product heterogeneity: An application to US motion picture exports. Journal of International Economics, 83(1), 14-26.

Harris, M., Ravid, S. A., Sverdlove, R., \& Basuroy, S. (2013). Intellectual property contracts-theory and evidence from screenplay sales. Working Paper, University of Chicago.

Hausman, J. A., \& Taylor, W. E. (1981). Panel data and unobservable individual effects. Econometrica, 49(6), 1877-1898.

Hennig-Thurau, T., Houston, M. B., \& Heitjans, T. (2009). Conceptualizing and measuring the monetary value of brand extensions: The case of motion pictures. Journal of Marketing, Special Section on Marketing Strategy and Wall Street, 73(6), 167-183.

Ho, J. Y. C., Dhar, T., \& Weinberg, C. B. (2009). Playoff payoff: Super Bowl advertising for movies. International Journal of Research in Marketing, 26(3), 168-179.

Holbrook, M. B. (1999). Popular appeal versus expert judgments of motion pictures. Journal of Consumer Research, 26(2), 144-155.

Hoskins, C., \& McFayden, S. (1991). The US competitive advantage in the global television market: Is it sustainable in the new broadcasting environment? Canadian Journal of Communication, 16(2), 207-224.

Hoskins, C., \& Mirus, R. (1988). Reasons for the US domination of the international trade in television programmes. Media, Culture and Society, 10(4), 499-515.

Jayakar, K. P., \& Waterman, D. (2000). The economics of American theatrical movie exports: An empirical analysis. Journal of Media Economics, 13(3), 153-169.

John, K., Ravid, S. A., \& Sunder, J. (2015). Performance and managerial ability: Evidence from the career-paths of film directors. Journal of Corporate Finance, forthcoming.

Lee, S. W. (2002). An economic analysis of the movie industry in Japan. Journal of Media Economics, $15(2), 125-139$.

Lee, F. L. F. (2006). Cultural discount and cross-culture predictability: Examining US movies' box office in Hong Kong. Journal of Media Economics, 19(4), 259-278.

Lee, F. L. F. (2008). Hollywood movies in East Asia: Examining cultural discount and performance predictability at the box office. Asian Journal of Communication, 18(2), 117-136.

Lee, F. L. F. (2009). Cultural discount of cinematic achievement: The Academy awards and US movies' East Asian box office. Journal of Cultural Economics, 33(4), 239-263.

Liu, Y. (2006). Word-of-mouth for movies: Its dynamics and impact on box office revenue. Journal of Marketing, 70(3), 74-89.

Luo, H. (2014). When to sell your idea: Theory and evidence from the movie industry. Working Paper, Harvard Business School.

Ma, J., Huang, D., Kumar, M. V. S., \& Strijnev, A. (2015). The impact of supplier bargaining power on the advertising costs of movie sequels. Journal of Cultural Economics (Special Issue on MotionPictures Economics, forthcoming).

Marvasti, A. (1994). International trade in cultural goods: A cross sectional analysis. Journal of Cultural Economics, 18(2), 135-148.

Marvasti, A. (2000). Motion pictures industry: Economies of scale and trade. International Journal of the Economics of Business, 7(1), 99-114.

Marvasti, A., \& Canterbery, E. R. (2005). Cultural and other barriers to motion pictures trade. Economic Inquiry, 43(1), 39-54.

Mas-Colell, A. (1999). Should cultural goods be treated differently? Journal of Cultural Economics, 23(1-2), 87-93.

McKenzie, J., \& Walls, W. D. (2012). Australian films at the Australian box office: Performance, distribution, and subsidies. Journal of Cultural Economics, 37(2), 247-269.

Moon, S., Bayus, B. L., Yi, Y., \& Kim, J. (2014). Local consumers' reception of imported and domestic movies in the Korean movie market. Journal of Cultural Economics. doi:10.1007/s10824-013-9214-X

Oh, J. (2001). International trade in film and the self-sufficiency ratio. Journal of Media Economics, 14(1), 31-44. 
Palia, D., Ravid, S. A., \& Reisel, N. (2008). Choosing to cofinance: Analysis of project-specific alliances in the movie industry. Review of Financial Studies, 21(2), 483-511.

Park, S. (2015). Changing patterns of foreign movie imports, tastes, and consumption in Australia. Journal of Cultural Economics (Special Issue on Motion-Pictures Economics, forthcoming).

Prieto-Rodríguez, J., Gutierrez-Navratil, F, \& Ateca-Amestoy, V. (2015). Theatre allocation as a distributor's strategic variable over movie runs. Journal of Cultural Economics (Special Issue on Motion-Pictures Economics, forthcoming).

Ravid, S. A. (1999). Information, blockbusters, and stars: A study of the film industry. Journal of Business, 72(4), 463-492.

Ravid, S. A., \& Basuroy, S. (2004). Managerial objectives, the r-rating puzzle, and the production of violent films. Journal of Business, 77(2), S155-S192.

Scott, A. J. (2002). A new map of Hollywood: The production and distribution of American motion pictures. Regional Studies, 36(9), 957-975.

Simonoff, J. S., \& Sparrow, I. R. (2000). Predicting movie grosses: Winners and losers, blockbusters and sleepers. Chance, 13(3), 15-24.

Sood, S., \& Drèze, X. (2006). Brand extensions of experiential goods: Movie sequel evaluations. Journal of Consumer Research, 33(3), 352-360.

Vogel, H. L. (2001). Entertainment industry economics: A guide for financial analysis (5th ed.). Cambridge: Cambridge University Press.

Walls, W. D. (1997). Increasing returns to information: Evidence from the Hong Kong movie market. Applied Economics Letters, 4(5), 187-190.

Walls, W. D. (1998). Product survival at the cinema: Evidence from Hong Kong. Applied Economics Letters, 5(4), 215-219.

Walls, W. D. (2009). The market for motion pictures in Thailand: Rank, revenue, and survival at the box office. International Journal of Business and Economics, 8(2), 115-131.

Walls, W. D., \& McKenzie, J. (2012). The changing role of Hollywood in the global movie market. Journal of Media Economics, 25(4), 198-219.

Waterman, D. (1988). World television trade: The economic effects of privatization and new technology. Telecommunications Policy, 12(2), 141-151.

Wildman, S. S., \& Siwek, S. E. (1988). International trade in films and television programs. Cambridge, MA: Ballinger.

Williamson, O. E. (1985). The economic institutions of capitalism: Firms, markets, relational contracting. New York: Free Press.

Williamson, O., \& Ghani, T. (2012). Transaction cost economics and its uses in marketing. Journal of the Academy of Marketing Science, 40(1), 74-85. 